\title{
In memoriam Prof. Dr. Jürgen Kiefer
}

\author{
Michael Hausmann ${ }^{1,2}$
}

Received: 4 September 2017 / Accepted: 6 September 2017 / Published online: 16 September 2017

(c) Springer-Verlag GmbH Germany 2017

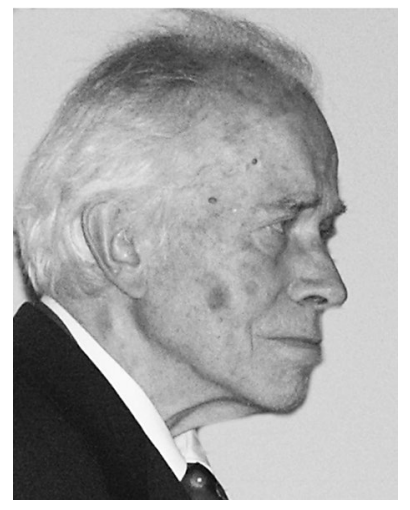

The "Gesellschaft für Biologische Strahlenforschung" (GBS; society for biological radiation research) is grieving for its founder and honorary member

Prof. Dr. Jürgen Kiefer

(November 29th, 1936-August 25th, 2017) who has unexpectedly died. From 1970 to 2002, he was a professor for biophysics at the Centre for Radiation of the Justus-Liebig University, Gießen, Germany. In addition, he was a professor for radiology in the Department of Veterinary Medicine from 1985 to 2002.

Besides his scientific contributions to radiation research, Prof. Kiefer was appointed to many national and international committees of radiation protection and safety. His initiative and his continuous engagement for radiation research and promotion of young scientists significantly contributed to the foundation of GBS in 1996. He was Vice President of GBS from 1996 to 1998 and President from 1998 to 2002. For his merits, he was awarded with the "FriedrichDessauer-Medaille" in 2003 and the "Ulrich-Hagen-Award" of the GBS in 2006.

On behalf of the executive council of GBS.

Compliance with ethical standards

Conflict of interest The author declares that he has no conflict of interest.

Michael Hausmann

hausmann@kip.uni-heidelberg.de

1 Kirchhoff-Institute for Physics, University of Heidelberg, Heidelberg, Germany

2 Gesellschaft für Biologische Strahlenforschung, Heidelberg, Germany 